\title{
4.1 'The Little Girl and the Wolf'
}

The difficulties involved in applying the dichotomies of form and content found in typical definitions of parody to the interpretation of parodic texts can be shown clearly by examining James Thurber's reworking of preformed material from 'Rotkäppchen' (KHM 26), entitled 'The Little Girl and the Wolf'. ${ }^{1}$ The text appropriates preformed material in the form of motifs, such as "a little girl", "a dark forest" and "a big wolf", ${ }^{2}$ but these intertextual references combine with the adoption of a terse narrative style to signal a failure to appropriate the convention of linear narrative which is characteristic of the tales collected in the $K H M$ :

One afternoon a big wolf waited in a dark forest for a little girl to come along carrying a basket of food to her grandmother. $^{3}$

Perception of discrepancies between formal, structural properties of 'Rotkäppchen' (KHM 26) and formal, structural properties of the new text by the reader, in this case involving the presence of motifs from 'Rotkäppchen' and the absence of other generic conventions, thereby sets up a contrast in 'codes', between the 'code' of preformed material from 'Rotkäppchen' (KHM 26) and the 'code' produced through the incorporation of this material into the structure of the parodic text. The reader can come however to understand this relationship be-

1 James Thurber: "The Little Girl and the Wolf" in: Fables for Our Time and Famous Poems Illustrated. New York: Penguin 1943, p. 4-5.

2 Thurber: "The Little Girl and the Wolf", p. 4.

3 Thurber: "The Little Girl and the Wolf", p. 4. 
tween 'codes' as proceeding not only on the basis of contrasting formal, structural properties, but also on the basis of the semantic and rhetorical functions which the preformed material can be interpreted as fulfilling in its new context. For example, the fact that the wolf is described as waiting for the little girl "to come along carrying a basket of food to her grandmother" can be read as a comic, metafictional indication that the wolf is aware of his own fictionality and future role in the plot, and could therefore be read as comment on the canonical status of the source of the preformed material.

Recognition of the presence of two 'codes' allows for multiple readings of the relationship between the 'code' of the preformed material and the 'code' of its incorporation into the parodic text. On the one hand, the relationship between 'codes' is ambivalent, since the 'Rotkäppchen' motifs are seamlessly integrated into the narrative, that is, since the preformed material is received as part of the structure of the new text. On the other hand, the simultaneous perception of a contrast in 'codes' has its basis in reader recognition of 'Rotkäppchen' motifs, reader knowledge of the preformed material and its source, and the expectations associated with this knowledge, since the preformed material is also received independently of the new text in relation to its source. The associations produced through reading this material in its new context allow for the perception of comic discrepancies between the preformed material, its source, and the context of its appropriation, through perception of this contrast in 'codes'. It is mainly through the perception of comic discrepancies between stylistic and structural features of the text and the conventions associated with the preformed material, and through the semantic and rhetorical functions which the preformed material 
can be interpreted as fulfilling in its new context that the reader can come to an understanding of the relationship between the text and the source of the preformed material.

The comic discrepancies between the preformed material and its new context range from the absence of structural Märchen conventions such as repetition and linearity through to the compact nature of the narrative, the incorporation of contemporary references into the narrative, and the comic device of having the plot break down upon the little girl's recognition of the wolf:

She had approached no nearer than twenty-five feet from the bed when she saw that it was not her grandmother, but the wolf, for even in a nightcap a wolf does not look any more like your grandmother than the Metro-Goldwyn lion looks like Calvin Coolidge. So the little girl took an automatic out of her basket and shot the wolf dead. ${ }^{4}$

Intertextual reference to 'Rotkäppchen' (KHM 26) is also made through a penultimate metafictional comment:

Moral: It is not so easy to fool little girls nowadays as it used to be. ${ }^{5}$

This moral can be read as humorous comment on the emancipation. of 'modern' women, but could also be interpreted as criticism of earlier versions of the tale, of Perrault's version, with its appended, explicitly didactic moral, and of Grimms'

\footnotetext{
4 Thurber: "The Little Girl and the Wolf", p. 4.

5 Thurber: "The Little Girl and the Wolf", p. 4.
} 
version, with its naive, helpless heroine.

Application of the dichotomy of form and content to the question of the genre of this text would lead to a designation of the text as a 'mixed form', since it is difficult to claim on the basis of the appropriated preformed material, consisting of motifs and a sequence of events involving the wolf, the little girl and the grandmother, that either content or form are retained. If the text is considered on the basis of textual strategy however, it can be seen that the appropriated preformed material gains a new range of functions in the context of the narrative. The text can be read as employing the appropriated preformed material for the purpose of entering into a dialogue with the preformed material and its source, on the basis of reader perception of discrepancies between the conventions associated with the source of the preformed material and the context of its appropriation, and metafictional signalling of reader expectations with respect to the source of the preformed material. Preformed material is thus appropriated and creatively 'refunctioned', allowing the text to be designated as employing parody due to the presence and coexistence of intertextual, metafictional, comic, critical and creative elements. Despite employing parody, the text can still be read as employing the material for its communicative potential, as contrafact, through the reference to the emancipation of 'modern' women, and for the purpose of comic contrast, as travesty, through the contemporary references to the Metro-Goldwyn lion and Calvin Coolidge. 